\title{
Environmental Sustainability: The Elusive Intellectual Capital Measurement Research Agenda
}

\author{
${ }^{1}$ Luke Amadi, ${ }^{2}$ Mina Ogbanga \\ ${ }^{1}$ Department of Political Science and Administrative Studies, University of Port Harcourt, Nigeria \\ ${ }^{2}$ Department of Sociology, University of Port Harcourt, Nigeria
}

\begin{abstract}
The dynamics of contemporary corporate asset suggest the expediency of evolving a measurement tool for corporate environmental sustainability as an important dimension of intellectual capital (IC). This is evident in current increase in corporate intellectual resources, technological assets and sophistry as an effective tool for advancing corporate competiveness. What has remained largely understudied is efficiency in resource use. A transition to environmental resource measurement is now critical to corporate development experts who seek to explore corporate efficiency. Personal surveys of environmental sustainability and Intellectual Capital measurement nexus were conducted with structured questionnaires to test formulated hypotheses for the research. A non-probability sampling procedure was chosen for the research sample. Findings suggest that environmental sustainability has been elusive in intellectual capital measurement. Policy discourse and alternative model to redress identified gaps was proposed.
\end{abstract}

Keywords: Intellectual Capital, Measurement Tools, Environmental Sustainability, Corporate Organization

\section{INTRODUCTION}

Technological advances would drive development in the 21st century, specifically Information Communication Technology (ICT) (Castells, 2000; Bontis, 2010). This finds palpable expression in understanding intellectual capital (IC) dynamics and its interface with a firm's natural environment. A key objective of the unfolding dynamic is how to measure environmental sustainability which is a central concept in a firm's transaction. Manuel Castells explains the inevitability of a new society emerging in the information age (Castells, 2000).Nick Bontis (2010) re-echoes that the common use of the terms such as intellectual capital, intangible assets, intangible management, knowledge capital, learning organizations, organizational learning, information age, knowledge era, information assets hidden value, and human capital hint at the increased importance knowledge assets have in organizations. Bontis(2010)suggests that these concepts provide novel explication emerging forms of economic value. Intellectual capital is a knowledge based system within which key organizational information and corporate dynamics is rearticulated.

A closer re-evaluation of the sustainability of companies in line with resource efficiency is now important for development of organizational tangible assets notably raw materials, fixed capital, and even managerial knowledge.

Leveraging environmental resourcefulness in wealth creation, corporate competiveness and profit maximization remains ever more critical in understanding the degree of environmental friendliness and dynamics of sustainable development. This goes beyond emphasizing the high tech innovations and technological advancement of companies. Within the corporate world, sustainability refers to the meeting of the needs of an organization's stakeholders' needs such as shareholders, employees, clients, communities etc, without compromising the organization's ability to meet the needs of future stakeholders. This organizational objective is important as it suggests that organizations must maintain both its needs and the needs of the stakeholders as well as the environment where the organization thrives (Dyllick \& Hockerts, 2002; Akhtar, etal; 2015).Companies engages in a number of business transactions currently involving technological imputes. For instance Akhtar, et al;(2015) emphasize that the Brundtland report also highlights the role of technology suggesting that developing countries need to work to develop their technological base for sustainable development. To develop the technological base, skilled and capable human resource is required. However relying solely on the 
technological innovation will entirely fail (Schor, 2005). This suggests a multifarious dimension to the study of IC and environmental sustainability.

A brief mapping of the evolution of IC points to its salient research agenda. Kasiewicz, et al;(2006:65) posits that the basis of the intellectual capital debate can be found in J. Rea's 1834 publication entitled; "The Sociological Theory of Capital". Bontis (2010) suggests that the earlier advancement of the concept emanated from the economist John Kenneth Galbraith who built on previous postulations of the economist Michal Kalecki in 1969 who stated that;

\section{I wonder if you realize how much those of us the world around have owed to the intellectual capital you have provided over these last decades (cited in Hudson, 1993:15; Bontis, 2010:1).}

Bontis (2010) argues that the term Intellectual Capital was also deployed by Peter Drucker (1993) to describe post-capitalist society. In the late 1990s a number of studies began to deploy the term IC in both corporate and other business transactions (Bontis, 1999a; 1999b).

Both Sveiby, (1997); Roos and Roos, (1997); Steward, (1997) and Bontis, (1999) have attempted to provide some insights in the measurement of IC. Accompanied by the methodological tools provided in subsequent researches (Edvinsson, 2000; Joia, 2000; Garcia, 2001; Bonfour, 2003; Sveiby, 2005; Lerro et al; 2008). However, despite promising offshoot and a number of ongoing empirical and theoretical studies on measurement of IC, generally relatively limited success has been made in the development of reliable IC measurement tool for corporate environmental sustainability.

Scholarly attention to measuring environmental sustainability in the context of a company's mode of business interaction has had a sketchy history since the 1990s. Environmental sustainability is among the three pillars of sustainable development encompassing social and economic.

Essentially IC and more recently its measurement has only promoted empirical research but not provided scientific objectivity as technical progress has remained minimal for a variety of reasons. The debates on novel approaches to measuring a company's environmental sustainability initiative are still pertinent though less pervasive among most companies. Recent studies support this proposition, Davidson and Hatt, et al; (2005) in their study on "consuming sustainability" identify deleterious effects of environmental consumption of companies and global corporate giants. Thus, one central argument that policy makers, firms and researchers should evolve a common standard for the measurement of environmental sustainability to check the effects of corporate environmental resource use on both human and material environment is marginalized at the time of revaluing existing studies on IC measurement dynamics.

This article argues that failing to understand the role of environmental sustainability in IC studies perpetuates growing challenge for corporate efficiency and sustainable natural resource use. The study further demonstrates that while IC both as a corporate tool and field of inquiry has provided evidence of poor measurement tools(Carrington,2013), its policy relevance for firms and practitioners needs to be broadened to meet growing demands of sustainable corporate transactions.

The article contends that there are still poor remedial strategies to fill the existing research gap, as a result, environmental sustainability measurement is yet to achieve desired ends. The debate advanced in this study seeks for an alternative, focusing efforts to include more perceptible tools and models of measurement to help essentialize environmental sustainability as a critical research tool for improved corporate performance. What follows is the conceptual framework, research methodology, policy recommendations and conclusion.

\section{CONCEPTUAL FRAMEWORK}

Intellectual capital research inquiry initially focused on defining IC and its components (Carrington, 2013). IC increasing accounts for both transactions and resources of corporate organizations formalized to replicate assets of higher value (Bontis, 1999; Sveiby, 1997).

There a number of studies suggestive of the rapid growth of the IC scholarship since at least the 1990s this is understandable as the world is at the information and communication age (Castells, 2000), thus debates associated with the concept of IC have received attention from academic researchers, practitioners, businesses and governments. More specifically, the benefit of IC to organizations has 
received significant attention, though no common method for its valuation has been determined (Carrington, 2013). Allee (2000) contends that an important contention in the use of intangibles particular within the work force is the challenge of converting intangible assets notably human knowledge reputation, business relationships, internal corporate structures, into negotiable forms of value.

The underlying assumption has been the absence of environmental sustainability measurement index which could add value to corporate organizations. An exploratory analysis of existing theoretical and empirical studies on measurement of IC is important to identify gaps in the literature. Sveiby (1990), provided the Invisible Balance Sheet, while the Balanced Scorecard, Kaplan \& Norton (1992), has also been in use among some corporate organizations. The Weighted Patents, Dow Chemical (1996), Technology Broker, Brooking (1996), Citation-Weighted Patents, Bontis (1996), Human Resource Costing \& Accounting, Johansson \& Nilson (1996), Economic Value Added (EVA ${ }^{\mathrm{TM}}$ ), Stewart \& Co (1997), Direct Intellectual Capital Methods (DIC) Return on Assets Methods (ROA). Similarly, there are a number of IC specific measurement tools. Allee (2000) provide the Intangible Value Framework, IC Rating (Edvinsson, 2000; Joia, 2000), Intangible Assets Statement Garcia (2001), ICdVAL ${ }^{\mathrm{TM}}$ Bonfour (2003).Intellectual Capital Statements for Europe (InCaS) InCaS Consortium (2006); Regional Intellectual Capital Index (RICI) Schiuma, Lerro, et al ;( 2008) have been quite useful measurement tools. An early assessment of IC measurement models by Pike and Ross (2004) conclude that none of the methods used to measure IC was compliant with measurement theory rather that they provide useful guidance for managers but they failure to agree on terminology and defining attributes on the measurement characteristics.

Bontis (2000:20) recounts that; "given the challenges of: i) trying to measure an intangible construct; ii) putting forth nascent efforts to conceptualize an IC domain; iii) establishing bi-directional causeeffect relationships, and iv) maintaining a reliance on the use of proxy variables, it should not be surprising that different companies' IC management systems contain any number of unconnected and unproved individual indicators". Ongoing sustainability debates also have challenges posed by prevailing "ecological modernization" perspectives in which the high income countries engage in unsustainable environmental consumption resulting to issues such as pollution and similar environmental degradation without environmental accounting (Worzel, 1994). One major oppositional research trajectory in sustainability debate is the fact that ecological modernization theorists ignore environmental cultural facets. Profit has primarily informed the foundational pursuits of companies to the detriment of the environment.

Considering environmental sustainability and interface with firm's transactions can offer novel insights into the understanding of dynamics corporate environmental accounting, the aim is to further contribute to broader elucidation of sustainability debate by offering alternatives to the exiting inexactness of IC and environmental sustainability measurement. Despite diverse IC scholarship and literature over the past two decades, corporate environmental sustainability measurement has been an under studied field of inquiry in the discipline. This paper demonstrates that there is scant studies that have provided theoretical and/or empirical correlation between IC as a measurement tool for environmental sustainability. This result in superficial conception of firm's focused and does not account for the changing realities of contemporary corporate performance and IC. The concept of practical intelligence have often been deployed as a proxy for tact knowledge (Sternberg, 1997; Crrington, 2013).

The emphasis has been shifting in the literature from an exclusive focus on corporate objectives to how such objectives are sustainably arrived at with emphasis on sustainable environmental resource use and its correlates such as eco efficiency, dematerialism, triple bottom-line, eco labelling, ecological footprint etc,(Hawken etal,1999;Hart,1997). Nevertheless, it has been argued that this new focus often, as well, neglects the dynamics of IC as a measurement tool for environmental sustainability.

The understanding of the concept of measurement of IC can take a number of interpretations aimed at exploring the relevance and utility of measurement in the IC arena, measurement could be looked at from another perspective, notably within the context of reshaping the conduct of others or assessing the ability to impact on corporate behavior rather than exploration and quantification of corporate assets in numerical terms (Carrington, 2013). How the existing IC measurement tools have reshaped the conduct of business in the context of eco -efficiency or eco labelling remains largely under studied. 
Flamholtz (1980) recounts important strand of measurement stating that the principle purpose of measurement within organizations is to influence the behavior of people, their perceptions, motivations, decisions and actions. Most companies are yet to grapple with the basics of businessdriven knowledge and its measurement. The pursuit of ecological justice becomes problematic for firms were environmental sustainability measurement is increasingly elusive. This has been primarily an attribute of the primacy of profit maximization and capital accumulation as tenets of neo liberal order.

Harvey(2005) asserts that such unequal access to resource use are inherent in the neoliberal policies as it allows individual concern within wider social forces, and in particular reasserts the existence of gap between the affluent and poor by re-circulating material possessions in the hands of the most powerful and affluent persons to the detriment of the poor. IC both as organizational tool and research agenda is crucial in developing corporate products and services processes of a firm (Kogut and Zander, 1996; Teece, 1998; Roos, etal; 1998; Carrington, 2013). Sustainability on its part both as pedagogical tool and research agenda conveys some importance that demands scholarly attention. This thinking is consistent with debates that propose a more efficient resource consumption pattern(Davidson and Hatt,etal;2005;Hobson,2003;Hart,1997; The Brundtland Report,1987; UN,Agenda,21). The Brundtland report (1987:7) observes that contemporary time is confronted with withdrawal from environmental and social concerns down to complex problems involving human survival: including environmental issues such as growing ecological issues, ozone depletion, desertification etc.

Stehle, et al; (2011) analyzed some objective shifts in understanding "value added intellectual coefficient (VAIC) method" as an indicator of IC. They also look in details at how IC is explicated and studies with the methodological tools of approach, they examined the relevance of conceptual, methodological, theoretical and empirical rigor involved in IC studies. Furthermore, the findings correlate earlier studies that attempts to provide measurement tools for the study of IC (Roos, et al. 1997; Seveiby, 1997, 2000, 2005; Carrington, 2013). Given the realities of corporate behavior, the persistent challenges of evolving a common global sustainable economy which the earth could provide with an indefinite support remains at issue (Hart, 1997).

The support system remains a critical issue in studying the earth's carrying capacity and related environmental risks implicit in corporate existence and human survival (Goodland,1995).The concern on minimization of corporate risk as a fundamental drive to corporate transactions and investment has been given attention(Weatherly,2003).

However, concern could arise that a firm's corporate objectives might run counter to environmental sustainability dynamics (Dressen, 2003). This in turn may put humans at risk especially in the poor societies.

Such experiences are discernible in the recent Grupco Mexico pollution and environmental pollution by oil multinational corporations (MNCs) in the Niger Delta, Nigeria. A critical break from environment is discernible from the classification of organizations' capital including human capital, social capital, customer capital and structural capital, Weatherly (2003:3) attempts a partial exploration of "the dynamics of an organization's total capital environment" and contends that; "It is important to note that a business is not just a storehouse 6 for knowledge, but a viable, dynamic environment. Vital relationships exist throughout an organization and interactions occur with varying degrees of intensity to ensure that knowledge (the tacit knowledge of the group found in the form of organizational culture, the explicit knowledge of an individual, or the structural knowledge of a data warehouse) gets converted from one form to another through, perhaps, multiple transformations, all for the purpose of adding value". Despite her supposition of a preference for human capital, how such "values" are added in the context of sustainability is plausible but largely elusive.

Conversely, Martinez García De Leaniz and Rodríguez Del Bosque (2013), argue that social sustainability is critical to the corporate reputation of a firm. A brief review of relevant literature, represents a "sustainability dilemma" for firms. When analyzing various theoretical models of intellectual capital, two key advances of its understanding is discernible namely; the tangible and intangible assets. The environmental factors where firms derive their material resource such as raw materials and how such materials are used are minimally examined which constitute the core of corporate sustainability within the dialectics of eco -efficiency. This constitutes a critical research agenda to benchmark inefficient resource use by companies - both service and manufacturing. 
Such studies will be helpful to comprehend the importance and uses of naturalresources and how IC can help redirect core resurgent trends and the logic of corporate resource exploitation in relation to the natural environment. This debate is consistent with recent debates on environmental sustainability (Shiva,1997 ;Hart,1997; Hawken,etal;1999;Davidson and Hatt, et al;2005; Collier,2010; Amadi,etal;2014).This is relevant in institutionalizing corporate environmental sustainability strategies into the business world.

Against the backdrop of the relevance of environmental sustainability to corporate production and services dynamics, environmental sustainability perception and inclination of companies are seemingly bleak. For instance in production dynamics of companies In today's knowledge-based economy, it has been argued that IC is the major driver of performance in an organization and that IC can be leveraged to create and sustain a competitive advantage (Carington,2013 ).Significantly, considerable studies and volume of writings have drawn attention to challenges of corporate environmental sustainability(Kotten,1995;Hart,1997;Hawken,et al;1999).The important study on corporations and dynamics of resource exploitation have been significant in exploring Ic dynamics in relation to sustainability (Kotten,1995).The debates of scholars of "ethics of sustainability" is readily discernible (Kibertetal;2012;Gasper,2012). The contention is to draw more ethical attention to "consumption of natural resources by firms. thus an engagement in measurement of IC could further a more objective understanding of the sensitivity of the environment. Thus, this research inquiry is important to researchers and policy makers who seek for more result oriented and valid measurement tools for IC in the context of corporate environmental sustainability and overall understanding of environmental sustainability.

The existing research lag and evidence of poor empirically valid and non-specific IC tools for measurement of environmental sustainability indicators could have significant effects on both companies and the human environment. The literature explored in this debate is by no means exhaustive .However, based on the brief review we formulate the following hypotheses;

$\mathrm{H}_{1}$ : Environmental sustainability measurement impacts a firm's performance.

$\mathrm{H}_{2}$ : Environmental sustainability measurement does not impact a firm's performance.

\section{Methodology}

\subsection{Data Collection and Sample}

Personal surveys of selected multinational oil companies (MNOCs) in the Niger Delta were conducted within the period January to September, 2014 using a structured questionnaire in order to test our formulated hypotheses. To design the research sample, a non-probability sampling procedure was chosen (Trespalacios, Vázquez \& Bello, 2005; Pérez and del Bosque, 2013). Particularly, a convenience sample was used. To guarantee greater representation of the data, a multistage sampling by quotas was made by characterizing the population according to the criteria relevant to the research: IC and environmental sustainability measurement. From the target sample of 400 questionnaires, 382 questionnaires were completed, 18 were discarded as incomplete. Hence, the final response rate was $95.5 \%$. The final sample consists of 186 females Senior Managers (49\%) and 196 midcareer staff $(51 \%)$.

The oil sector was our choice of sectorial study for the research as oil resource exploration and exploitation has a higher tendency for environmental degradation and ecological breakdown such as oil spill, gas flaring, pollution, acid rains etc(Okon \& Egbon, 1999; Uyigue \& Agho, 2007; Eregha \& Irughe,2009; UNEP,2011; Kadafa,2012;), poverty(UNDP,2006), resource curse(Amadi and Alapiki,2014).

Importantly, this research field helps us avoid the limitations of non- participatory data collection, since data were administered and directly collected in real conditions of use. Preliminary versions of the questionnaire were administered to a convenience sample of 18 corporate executives, and pretest results were used to improve measures and design and appropriate structure for the questionnaire. Existing well-established multiple-item 7-point Likert scales were adopted to measure our variables (Pérez and del Bosque, 2013). Sustainability dimensions were measured using a seventeen-item scale from Martínez, Pérez and Rodríguez del Bosque (2012; 2013). To finish, we measured corporate sustainability with four items developed by Ahearne, Jelinek and Rapp (2005) as adopted in Martínez, Pérez and Rodríguez del Bosque (2013) . 


\subsection{Validity of Instrument}

In order to achieve the objectives of our research, the study followed Pérez and del Bosque (2013) whose study was built on Anderson and Gerbing's (1988) two-stage procedure. First of all, the goodness of the measurement instrument's psychometric properties was analyzed by a confirmatory factor analysis and secondly, the structural relations among the theoretically proposed latent variables were analyzed through a structural equation model (Pérez and del Bosque, 2013). Both the measurement model and the causal relations model were estimated using the maximum likelihood method with robust estimators using EQS v.6.1 (Pérez and del Bosque 2013).

The psychometric properties (reliability and validity) of the measurement instruments were assessed by a confirmatory factor analysis containing all the multi-item constructs in our theoretical framework by using EQS v.6.1 (Bentler, 1995; Pérez and del Bosque, 2013). The reliability of the measurement scales proposed was evaluated using the Cronbach's alpha coefficient and by an average variance extracted (AVE) (Hair,et al;2010). The values of these statistics exceed the minimum recommended values of 0.7 and 0.5 , respectively (Hair et al., 2010), which confirm the internal reliability of the model. In addition, all the items are significant at a confident level of 95\% and their standardized lambda coefficients exceed 0.5 (Steemkamp \& Van Trijp, 1991), confirming the convergent validity of the model. Finally, in order to confirm the discriminant validity, the confidence intervals for the correlation of the constructs are estimated and compared with the unit. In none of the cases did the intervals contain the value 1 . Therefore, the measurement model proposed is correct. Finally, the goodness of fit of the analysis was verified with the Satorra-Bentler ${ }^{2}\left(\mathrm{~S}-\mathrm{B}{ }^{2}\right)(\mathrm{p}<0.05)$ and the comparative fit indices NFI, NNFI, IFC and IFI, which are the most common measures for confirmatory tests (Uriel \& Aldás, 2005). All values were greater than 0.9 (Bentler, 1995), indicating that the model provides a good fit.

\subsection{Hypotheses Testing}

The standardized coefficients and the formulated hypotheses were tested. $\mathbf{H}_{1}, \mathbf{H}_{2}$ were examined in relation to the data gathered from the field and theoretical evidence suggestive that environmental dimension of sustainability has a positive direct effect on corporate performance. This study shows that environment is considered to be the most important dimension to enhance corporate sustainability $\left(\beta=0.326^{*} ; \mathrm{p}<0.05^{*}\right)$.

The null hypotheses which states that environmental sustainability measurement does not impact a firm's performance is rejected. This is perceptible as the Niger Delta has a high rate of environmental degradation (UNEP, 2011; UNDP, 2006; Amadi and Alapiki, 2014). These results give credence to the fact that environmental sustainability measurement will ameliorate the rate of deleterious consumption of the environment and resource use by corporate organizations such as the multinational oil companies (MNOCS) in the Niger Delta and further support the research theme which aims to argue for a model of IC for the measurement of environmental sustainability for firms.

\section{RESUltS AND ANALYSIS}

Data gleaned from structured questionnaires from respondents indicate that environmental sustainability measurement has been elusive among multi- national oil companies (MNOCs) in the Niger Delta. While these mostly explicit IC measuring tools offer the advantage of innovative approaches to IC measurement, their actual contribution to effective and specific IC measurement within the field of environmental sustainability is less clear. Organizational decisions and choices are often informed by socio-cultural knowledge other than environmental sustainability knowledge. Most of these socio cultural factors as Harlow (2013) argued are difficult to measure. He reports that the degree of explicit codification- more manuals, patents or product plans do not presage success at firms and does not indicate that the knowledge encoded is valuable or unique. Firms may have extensive libraries of codified knowledge (patents) that is rarely accessed or is by passed by unmapped tacit processes.

This is another prior research that indicates a strong need for a new conceptualization of firm intellectual property development driven by people and processes the theoretical and empirical literature explored revealed that there is a gap in empirical study between environmental sustainability and measurement of IC. This supports the finding of Atkinson. Morgan, et al;(2006:84) identified 
similar challenges in measuring corporate responsibility demonstrating that the equity dimension of the triple bottom line is undeniably the most difficult area to quantify unambiguously. Additionally, it has been argued that poor understanding of a firm's external environment is an issue. Drucker (2006) reports the importance of corporate environment to the over- all corporate performance.

Alack of empirical information on the effect of Knowledge Management Systems (KMS) that includes both tacit and explicit methods has given rise to the notion that companies resort to technological preferences meant to secure and circulate mainly explicit knowledge (Almeida and Kogut 1999; Harlow,2013). This is readily discernible from the existing study on empirics of IC. From a number of models that have been developed over the years to measure IC and its constructs such as the Invisible Balance Sheet and the growing scholarship on measuring IC as explored, findings suggest that corporate sustainability indicators are marginalized as existing literature on IC predominantly focus on technological pedagogical tools.

Similarly, a number of recent studies have suggested that technological innovations have had inroads into most corporate organizations as such solutions are preferred (Schor,2005).Evidence of some well- known technological solutions include the hydrogen economy and bio-mimicry (McDonough and Braungaurt,2002; Beynus, 2002; Schor,2005). Schor (2005:310) observed that the notion of technological preferences reflect the interest of corporate organizations pointing to what she termed the economist's"free lunch".

However most periphery societies are yet to be integral part of corporate technological innovations. Schor(2005) argues that relying entirely on technology will fail as there is high preference to boost the scale of consumption which in her views has been too powerful

Conversely, thepoor and non- technologically advanced societies have been missing out on technologically based innovation. This dichotomy makes the reliance on technology an inequitable model. However, Ans off (1990) proposes that a stated intellectual capital strategy for technology firms becomes more important as firms participate in more "turbulent" environments (Cited in Harlow, 2013). Turbulent environments that are those where lack of visibility to the future and increasing complexity dictate a managerial climate of strong competence, high rewards and flexible risk taking (Harlow, 2013). There is evidence of poor specific environmental sustainability tool for IC measurement. This could negatively impact performance, suggesting policy redirection in the context of enlarging IC measurement tools. This finding may suggest that corporate performance is affected by non- measurement of environmental sustainability. An important correlation of this proposition is that poor application of corporate sustainability dynamics could taint or deplete resources badly needed for efficient production and related performance of a firm. This inverse relationship suggests that corporate organizations with weak corporate environmental sustainability standards will result to poor commitment to eco efficiency.

On September 2014, Grupco Mexico a multinational firm caused a massive environmental pollution in Mexico which is hazardous to humans and vitiates corporate integrity.

The Royal Dutch oil company Shell, has also caused massive oil spill and similar environmental pollution ongoing in the coastal Niger Delta Nigeria, the 2011 UNEP report shows that it will take between 20 to 50 years for a clean-up. This has affected corporate environmental sustainability model. Hart(1997) suggests an integrated environmental approach which should transcend "competency development" and extend to reshaping the company's interaction and relationship with customers, competitors, the supply chain, policy makers and all relevant stakeholders. The results of this analysis demonstrates in the affirmative the fundamental question of whether measurement of IC has a significant and positive impact on corporate environmental sustainability.

These results support the findings of Morgan, etal; (2006) which posit that companies with strong corporate performance measurement system that brings into existence corporate sustainability, provide relevant and critical enhancement performance pertaining environmental resources and capability. They observed that to better understand the ecology bottom line, new kinds of metrics are beginning to be developed for quantifying the costs and benefits of diminishing or enhancing a set of ecosystem services currently provided by the natural environment. The rational for evolving sustainable development measurement model has been amply demonstrated as the argument supports an earlier call from Kaplan and Norton (1996: 21) who asserted that "if you can't measure it, you can't manage it". This finding has a substantial significant relationship between measurement of IC 
and performance and corroborates a number of other empirical studies that referred to performance measures.

These studies prove insights that support the premise that entities that measure their intellectual capital appear to be more beneficial in their overall performance as these intellectual capital measures are important drivers of long term economic success (Carrington, 2013). Measurement of IC thus should be enlarged to significantly provide plausible understanding of corporate efficiency and performance dynamics. Svei by (2005) suggests four categories of intellectual capital measurement techniques; direct intellectual capital methods, scorecard methods, market capitalization methods and return on assets methods. So, the aim of this paper is to explore how best IC measurement tools could be reframed to a more specific measurement of corporate environmental sustainability. How has IC measurement tools improved in the practice of corporate sustainability? Can improved IC practice in the context of eco-efficiency facilitate corporate performance? While the prevailing IC studies have laid a formidable background which demonstrates important evidence to advance the study and in particular the grasp of IC, some empirical lapses are discernible with respect to the flexibility and divergent nature of IC measurement. This gap in our knowledge is one of the areas that need to be filled in order for a clearer understanding of IC measurement.

\section{Conclusion}

This research is inspired by the most fundamental objective that argues that the measurement of IC can be successful in ameliorating anthropogenic choices of firms which could be antithetical to human environment. Thus, corporate choices should be guided by pro -environment and pro people policy direction. It posits that strategic efforts of researchers and firms could be influential in evolving a well- worn approach to check deleterious environmental resource use which affects firm's organizational efficiency and taints sustainable resource consumption. Harlow (2013) identified existing generic strategies by firms but argued that the strategies are driven by the use of firm-specific competencies gained through effective use of knowledge. Within these strategy types, goals such as new product and financial results are intertwined with the choice of innovation sub-strategies (i.e., first to market or follower). This research sought to propose a novel research goal for IC in the context of sustainable development. The impact of process of measuring IC on improved performance of firms could be actualized through incorporation of salient pillars of sustainable development such as environmental, economic and social. The exploration of existing theoretical and empirical data enabled the researcher to validate a number of studies and approaches that can be used to measure IC in relation to environmental sustainability. The analysis of data indicated a gap in literature on specific IC measurement tools that emphasizes strands of environmental sustainability measurement such as eco-efficiency, greening, dematerialism, eco labeling, ecological footprint etc. The study argued that IC measurement will impact significantly on a firm's overall performance. Another contribution of the research, especially for those firms in the manufacturing sector, is that production and manufacturing dynamics should now draw closer attention to eco -efficiency. The recognition of the benefits of measuring IC, as this study supports earlier findings of the impact of measurement of IC on performance, centers on equitable and more just use of the natural resources (Shiva,1997;Collier,2010). This brings firm's corporate mission, vision and objectives to the understanding of the long term benefits of environmental sustainability and therefore management within the corporate world should develop integrated measurement systems that incorporate IC factors within their entire facets. This study demonstrated linkages between measurement of IC and corporate performance. However, the research derives largely from previous theoretical and empirical data the reasons are understandable to explore what has been said before on the subject, identify possible gaps and develop new research direction aimed at filling identified gaps. This literature tries to understand the concepts of IC measurement and how these relate to environmental sustainability.

Marr et al; (2004) creates some important insights in the IC research agenda as the re-echo that it has become increasingly important to understand the corporate, academic and research focus of IC which practitioners should observe stressing the importance of corporate disclosure as both useful and critical for the understanding of the real inclination and motives of companies in business and beyond this provides corporate benefits and reputation.

Gaps in the current research reveal that there is absence of empirical validation of which IC methods (either explicit or tacit or a combination of both) are more or less effective, and there has been little research that looks at the relationship of IC to environmental sustainability strategies of firms where 
concepts such as corporate greening, eco labeling and eco efficiency could be specifically measured. Furthermore, the methodological tools in the literature have a number of flaws for instance there are evidence of validity problems at arriving at generalizations in measuring socio-cultural phenomenon which are difficult. A firm's overall corporate environmental sustainability strategy is largely a function of a firm's commitment to resourcefulness, that could be strategic, and environmentally value laden. The analyses show, that the efficiency of the firm's production base has a whole lot to do with human and non- human environments.

\section{REFERENCES}

Akhtar C Ismail K,Ndaliman M,Hussain J,Haider M(2015) Can Intellectual Capital of SMEs Help in Their Sustainability Efforts Journal of Management Research ISSN 1941-899X, Vol. 7, No. 2

Allee, V. (2002). The Future of Knowledge Increasing Prosperity through Value Networks

Butterworth-Heinemann

Allee, V. (2008). Value Network Analysis and value conversion of tangible and intangible assets

Journal of Intellectual Capital Volume 9, No. 1, pp. 5-24

Booth, R. (1998). The measurement of intellectual capital. Management Accounting UK 76(10): 2628.

Bontis, N. (1999). “Managing organizational knowledge by diagnosing intellectual capital:framing and advancing the state of the field"', International Journal of Technology Management, Vol. 18 No. 5-8, pp. 433-62

Bontis, N., Dragonetti, N., Jacobsen, K. \& Roos, G. (1999) “The Knowledge Toolbox: A Review of the tools available to measure and manage intangible resources". European Management Journal, $17,391-402$

Bontis N (2010) Assessing knowledge assets: a review of the models used to measure intellectual capitalInternational Journal of Management Reviews pp1-24

Brooking, A (1997). Intellectual capital. International Thomson Business Press.

Carrington, D.(2013). An Empirical Study on the Impact of the Process of Measuring IC on

Performance Electronic Journal of Knowledge Management Volume 11 Issue 4

Collier, P. (2010).The Plundered Planet: Why We Must--And How We Can--Manage Nature for Global Prosperity, Oxford Press

Daily, C and Ehrlich, P.(1996).Socioeconomic Equity,Sustainability, and Earth's Carrying Capacity.Ecological Application,Vol6,No.49,91.1001

Davidson, D.\& Hatt. K, etal., (2005). Consuming Sustainability Critical Social Analysis of Ecological Change. Fernwood publishing.

Dressen, P.(2003)."Eco-Imperialism: Green Power, Black Death.Free Enterprise Press: Belleview,WA.

Drucker, P.(2006).The Effective executive The Defining Guide to Getting the Right Things Done Harper Collins Publishers, NY.

Dzinkowski, R. (2000). The measurement and management of intellectual capital: an introduction. Management Accounting (UK), 78(2), February, pp. 32-36.

Edvinsson, L.\& Malone, M. (1997). Intellectual Capital, Harper Business, NY.

Gasper, D. (2004).The Ethics of Development: From Economism to Human Development Edinburgh University Press, 2004 - pp- 255

Goodland, R. (1995).The Concept of Environmental Sustainability.Annual Review of Ecology and Systematics, Volume 26,1-24.

Hart, S. (1997).Beyond Greening:Strategies for a Sustainable World .Harvard Business Review.

Harvey,D.(2007).A Brief History of Neoliberalism. Oxford University Press.

Hawken P, Lovins A, Lovins L. (1999). Natural capitalism: creating the next industrial revolution. Boston (USA): Little, Brown and Company.

Hobson, K.(2003). Consumption, Environmental Sustainability and Human Geography in Australian: a Missing Research Agenda? Australian Geographical Studies 41(2)148-155 
Kaplan,R \& Norton ,D .(1997). Balanced Scorecard: Strategien Erfolgreich Umsetzen (Gebundene Ausgabe)

Kibert. C, Thiele. L, Peterson .A and Monroe .M, ( 2012). The Ethics of Sustainability .http ://scholar .google. com/scholar? q=related: tYgJRAQtgv.

Luthy, D(1998). "Intellectual capital and its measurement." Proceedings of the Asian Pacific Interdisciplinary Research in Accounting Conference (APIRA), Osaka, Japan.

Martinez García De Leaniz, P.; Rodríguez Del Bosque, I. (2013). Intellectual capital and relational capital: The role of sustainability in developing corporate reputation. Intangible Capital, 9(1): 262-280. http://dx.doi.org/10.3926/ic.378

Matos ,F.(2013) A Theoretical Model for the Report of Intellectual Capital Electronic Journal of Knowledge Management Volume 11 Issue 4,PP.339-360

McDonough W and Braungart, M. (2002). Cradle to Cradle: Remaking the Way We Make Things.North Point Press.

Merges R, Menell,P , Lemley M(2006)Intellectual Property in the Technological Age, 3rd ed.;NY: Aspen Publishers.

Morgan E, Levitt R and Malek W, (2007). Executing Your Strategy .How to Break it down and Get it Done.Harvard Business School Publishing

Nonaka, I. \& Takeuchi, H. (1995). The knowledge creating company: How Japanese Companies Create the Dynamics of Innovation. N Y: Oxford University Press.

Paździor A and Paździor M (2012) Measurement of Intellectual Capital in a Company.Management Knowledge and Learning International Conference .

Quintas, P., Lefrere, P. \& Jones, G. (1997) Knowledge management: A strategic agenda. Long Range Planning, 30(3), pp. 385-391.

Roos, J., Roos, G., Dragonetti, N. and Edvinsson, L. (1998). Intellectual Capital: Navigating in the New Business Landscape,University Press, New York.

Roos, G. and Roos, J. (1997). "Measuring Your Company's Intellectual Performance”, Long Range Planning, Vol. 30(3): 413-426.

Schor, J.(2005).Prices and quantities: Unsustainable consumption and the global economy, Ecological Economics 55, 309- 320

Schmidheiny ,S .(2000). Eco -efficiency, creating more value with less impact. Available at Http// www.wbcsd.org Accessed 8/11/2014

Shiva,V.(1997).Biopiracy The Plunder of nature and knowledge. Boston MA:South End Press

Stewart, T. (1997). Intellectual Capital: The New Wealth of Organizations. Nicholas Brealey Publishing, London

Sveiby, K. (1997). The New Organizational Wealth: Managing and Measuring Knowledge-Based Assets, Berrett-Koehler, New York, NY

UN, (1987). "Our Common Future" Brundtland Report, Oxford Press

UN, (1992). Report of the United Nations Conference on Sustainable Development Rio de Janeiro, Brazil

UNEP,(2013). Eco labelling what types of environmental labeling exist? Available at http://www.unep.org/resourceefficiency/Consumption/StandardsandLabels/Ecolabelling/tabid/10 1342/Default.aspx

Weatherly, L (2003) Human Capital — the Elusive Asset Measuring and Managing Human

Capital: A Strategic Imperative for HR Leslie A. SPHR HR Content Research Quarterly pp1-11

World Wide Fund (2014) Ecological Footprint Available at http:// wwf.panda.org/ about_our_earth/ teacher_resources/webfieldtrips/ecological_balance/eco_footprint/Aaccessed 7/12/2014

Worzel,R .(1994). Facing the Future; The Seven Forces Revolutionalizing Our Lives,Stoddart Publishing Co.Limited,34 Lesmill Road,Toronto Canada 